\title{
BMJ Global Health Addressing power imbalances in global health: Pre-Publication Support Services (PREPSS) for authors in low-income and middle-income countries
}

\author{
Clara Busse 다 , Ella August
}

To cite: Busse $\mathrm{C}$, August $\mathrm{E}$. Addressing power imbalances in global health: PrePublication Support Services (PREPSS) for authors in lowincome and middle-income countries. BMJ Global Health 2020;5:e002323. doi:10.1136/ bmjgh-2020-002323

Received 16 January 2020 Revised 23 January 2020 Accepted 27 January 2020
Check for updates

\section{(C) Author(s) (or their} employer(s)) 2020. Re-use permitted under CC BY-NC. No commercial re-use. See rights and permissions. Published by BMJ.

School of Public Health, Department of Epidemiology, University of Michigan, Ann Arbor, Michigan, USA

Correspondence to Dr Ella August;

eaugust@umich.edu

\section{ABSTRACT}

The contextual knowledge and local expertise that researchers from low-income and middle-income countries (LMICs) contribute to studies in these settings enrich the research process and subsequent publications. However, health researchers from LMICs are underrepresented in the scientific literature. Distally, power imbalances between LMICs and high-income countries, which provide funding and set priorities for research in LMICs, create structural inequities that inhibit these authors from publishing. More proximally, researchers from LMICs often lack formal training in research project management and in publishing peer-reviewed research. Though academic journals may value research from LMICs conducted by local researchers, they have limited time and financial resources to support writing, causing them to reject manuscripts with promising results if they lack development. Pre-Publication Support Service (PREPSS) is a non-profit, non-governmental organisation that works to meet this need. PREPSS provides onsite training, peerreview and copy editing services to researchers in LMICS who wish to publish their health research in peer-reviewed journals. Authors are not charged for these services. After receiving PREPSS services, authors submit their manuscript to a peer-reviewed journal. The PREPSS model is one of many interventions necessary to restructure global health research to better support health researchers in LMICs and reduce current power imbalances.

\section{INTRODUCTION}

Authors from high-income countries tend to dominate the author lists of publications describing research in low-income and middle-income countries (LMICs). Even when local authors are included, it is likely they are not in the influential first or last author positions. According to a recent review that analysed papers using data from sub-Saharan Africa, $14 \%$ had no local authors and only about half of first authors were local. Local author representation decreased if any of the collaborators were from the USA, Canada or Europe and it decreased even

\section{Summary box}

- Systemic inequities and power imbalances between high-income countries and low-income and middleincome countries (LMICs) shape disparities in health research authorship; authors from LMICs are greatly under-represented in scientific literature.

- While academic journals may value research from LMICs, their budgets do not allow for extensive writing support for authors from LMICs, forcing them to turn away manuscripts with promising research if they lack development.

- If authors from LMICs are unable to learn the skills necessary to initiate research studies and lead publications, they will not become independent researchers, thereby perpetuating the dominance of scientists from high-income countries.

- Pre-Publication Support Service (PREPSS) provides onsite training, peer-review and copy editing services to researchers in LMICs who wish to publish their health research in peer-reviewed journals. After receiving services from PREPSS, authors submit their manuscript to a peer-reviewed journal, and the support continues postpeer review to help the authors in their response to reviewer comments. The authors are not charged for these services.

further in collaborations with top US universities. ${ }^{1}$ Another review reported a similar trend in infectious disease research in Africa ${ }^{2}$ and this pattern has also been reported elsewhere. $^{3}$

Thus, even though great progress has been made since the early years of global health research $^{4}$ when foreigners controlled all aspects of the research process, structural problems that inhibit LMIC authors from publishing persist. If these authors are unable to learn the skills necessary to initiate research studies and lead publications, they will not become independent researchers, thereby perpetuating the dominance of scientists from high-income countries. ${ }^{5}$ Without the opportunity or support to develop professionally, 
these scientists from LMICs may never have the chance to set research priorities for their own country or region.

Manuscripts written without the experiences and perspectives of local experts will lack context and a rich interpretation of results. Our collective health suffers when neo-colonial research structures exclude the insights and leadership closest to these problems.

\section{SYSTEMIC INEQUITIES SHAPE PUBLICATION BARRIERS}

Systemic inequities and power imbalances between researchers from high-income countries and those in LMICs are at the root of authorship disparities. ${ }^{6}$ The symptoms are easy to see: lack of diversity on journal editorial boards and among peer reviewers, to name a few. ${ }^{67}$ Where resources for research capacity are limited, research writing instruction and support are often not available, giving rise to poor manuscript preparation. ${ }^{8}$

Lack of English language proficiency, country-specific variations in written English norms and scarcity of scientific mentorship may prevent even high-quality research from publication in scientific journals. ${ }^{8-10}$ Unspoken conventions, such as essential content to include in a cover letter and how to convey the proper tone in a manuscript, are difficult to decipher without a network of mentors and advisors from the published scientific community. ${ }^{11}$

While journals may value research from LMICs, their budgets do not allow for extensive writing support for authors, forcing them to turn away manuscripts with promising results if they lack development. Although select journals offer some manuscript preparation support for a fee, there still exists a great unmet need for writing instruction, and a lack of opportunity for extensive revision and resubmission. ${ }^{8}$

\section{THE DEEPER PROBLEM OF 'GAZE'}

Inequalities between high-income and LMIC researchers do not manifest only in authorship affiliations and in the framing of research findings. They can materially change the story told in research publications. In his recent editorial, Abimbola ${ }^{12}$ highlights these power imbalances between the high-income countries that provide funding and set the research agenda and the LMICs where the research is actually conducted. He explores how the intended audience (what he refers to as 'gaze') changes—and can even corrupt— the narrative.

If a local LMIC researcher writes for the foreign gaze, Abimbola asserts, how the story is told changes. And, inevitably, how the story is told changes the story itself. A local researcher's decision to write in English or a local language and their choice of publication outlet will inevitably alter the message. A story written for a local gaze will offer complexity and nuance that can be lost when framed for an international gaze. An article for a foreign gaze can become overly academic and lose sight of practical in-country solutions.
And, as explored by both Abimbola ${ }^{12}$ and Mbaye et al in their recent publication, ${ }^{2}$ solutions valued by a local researcher tend to be qualitatively different than those of a high-income country researcher. Whereas short term, often external solutions are favoured by foreign funding agencies, local citizen researchers favour the organic, internal means that can take more time. This deeper issue of gaze will not be resolved until power shifts into the hands of local researchers, and this cannot happen until research capacity is strengthened.

\section{PRE-PUBLICATION SUPPORT SERVICE: ADDRESSING INEQUITIES AND BARRIERS}

Pre-Publication Support Service (PREPSS; https://sites. google.com/umich.edu/prepss) is a non-profit, nongovernmental organisation that works to address these disparities in global health research. PREPSS provides peer review and copy editing services to researchers in LMICs who wish to publish their health research in peerreviewed journals. Authors are not charged for these services. Established, skilled researchers volunteer their time to work with LMIC authors prior to manuscript submission, thereby increasing the likelihood of acceptance and publication.

To our knowledge, there is no programme or process like PREPSS. While other prepublication peer-review services exist, they are distinct from PREPSS in that they have a topical focus other than global public health and medicine, or their services are not free to authors, or they do not provide copy editing.

PREPSS has a twofold mission. First, we aim to increase representation in the academic health sciences literature of authors from LMICs. Second, we work to raise awareness of inequities and social justice in global health research among the next generation of researchers.

To achieve the first part of our mission, we assist authors from LMICs in writing and publishing their original research in peer-reviewed journals. Most often, this support takes the form of onsite training, post-training peer review and copy editing (see tables 1 and 2 for an overview of our services and typical onsite training agenda, respectively). All of these services help to educate authors from LMICs about the research writing and publication process. In the onsite training, through formal writing education, authors learn how to effectively share their research findings with the scientific community. During peer review and copy editing, authors learn from peer comments and practice the revision process. Taken together, these services facilitate the professional development and independence of researchers from LMICs.

The second part of our mission is fulfilled through the training we provide to new PREPSS peer reviewers. While researchers with a terminal degree such as a $\mathrm{PhD}$ or MD apply to join PREPSS with a simple request, doctoral candidates are required to complete our peer reviewer training. Practically speaking, doctoral candidates make 
Table 1 Services typically provided by PREPSS in our three author support programme

\begin{tabular}{lcc}
\hline Research Training Programme & Journal Partners Programme & Research Partners Programme \\
\hline Pretraining webinar & Multiple rounds of peer review & Pretraining webinar \\
Three-day onsite training & from two peer reviewers & Three-day onsite training \\
Follow-up support & Copy editing & Follow-up support \\
- Multiple rounds of peer review from two & - Multiple rounds of peer review from \\
$\quad$ peer reviewers & two peer reviewers \\
- Copy editing & - Copy editing
\end{tabular}

PREPSS, Pre-Publication Support Service.

excellent peer reviewers: they are enthusiastic about learning the required skills and once trained, are comprehensive in their reviews. Additionally, within approximately 3-5years, doctoral candidates typically transition to research or faculty positions. Continued affiliation with PREPSS across this transition has the potential to shape the field of global health research. In our training, we teach skills that support effective peer review as well as cross-cultural communication skills. Our training also addresses authorship and inequities in academic publishing in global health research. To ensure highquality peer reviews, we generally pair one non-student reviewer with one student reviewer, allowing the student to learn from the senior reviewer's work.

\section{PROCESS AND POLICIES}

We aim to strengthen the capacity of LMICs to independently produce research by working only with authors who have strong research skills in place. ${ }^{13}$ We work with three types of partners, described below. Our services vary slightly depending on the partner type (see table 1 for the services we provide). Authors are not charged any fees in any of our programme.

\section{Research Training Programme}

In this programme, started in August 2017, we work with authors who received rigorous research training by a partner organisation. We build on this training, focusing on writing and publication. Funding for this activity is provided by the partner organisations. Our primary Research Training partner is the Center for Reproductive
Health Training at the University of Michigan Medical School; this organisation partners with academic institutions in low-income countries to strengthen capacity for life-saving reproductive health services. They provide comprehensive training on conducting reproductive health research and PREPSS provides the final stage of this training on manuscript writing and publishing.

\section{Journal Partners Programme}

We launched this programme as a pilot with two journals in July 2019. Journal editors identify submissions from LMICs that are promising but were rejected because they did not meet the journal's standards. PREPSS works with authors to improve these manuscripts, after which authors resubmit to the journal. Author support packages from PREPSS include peer-review and copy editing services. Once we demonstrate the effectiveness of this pilot initiative, we will seek financial support from external funders and publishers to create sustainability.

\section{Research Partners Programme}

We also support authors who are part of large, grantfunded research projects. Financial support for this initiative comes from the partner's research project. Our newest partner is a Gates-funded research project investigating strategies for the reduction of anaemia in women who smoke fish in Ghana. We trained the Ghanaian investigators immediately after they finished data collection and we are now awaiting manuscript submission for follow-up support.

Table 2 Typical agenda for PREPSS onsite training workshop

\begin{tabular}{lll}
\hline Day $\mathbf{1}$ & Day 2 & Day $\mathbf{3}$ \\
\hline Choosing a target journal and writing & Methods section & Discussion section \\
to your audience & Results section & Writing a compelling cover letter \\
Top reasons for manuscript rejection & Developing a social media presence & Effectively responding to journal peer \\
Authorship standards and difficult & - Titles & reviewers \\
situations & Creating effective visuals & Individual consultations \\
Introduction section & & \\
Effective research questions & \\
Submitting your paper to a journal via &
\end{tabular}

Each topic includes a brief presentation and a hands-on activity.

PREPSS, Pre-Publication Support Service. 
The way in which we work supports our mission to increase research independence, author representation and equity in global health research. We only review original research papers, because original research is most helpful in attaining independence. The first author of submissions to PREPSS must be from an LMIC and the data must come from that author's country of residence. Notably, researchers from LMICs self-select to work with PREPSS based on their aspiration to publish their research in a peer-reviewed academic journal. Further, these researchers select the target journals for the manuscripts they submit to PREPSS, whether local or global.

We acknowledge the need to notice and amplify local health conversations in non-academic channels ${ }^{12}$ and PREPSS does not work counter to this aim. Indeed, PREPSS works with authors from LMICs who are attempting to engage in a local or global discourse about the health challenges in their countries or local settings.

Importantly, other than the fact that we only support English-language publications, we do not insert ourselves into the work of authors that we are supporting. PREPSS peer-reviewers are prohibited from participating as authors on the papers they review.

Without varied perspectives, including those from LMICs, we would not be successful. We have worked to create a diverse peer-reviewer team; our peer reviewers hail from all parts of the world, including Ethiopia, Kenya, Liberia, Ghana, South Korea, China, Mexico, India, Costa Rica, Canada and the USA.

PREPSS has formalised the currently informal, oneon-one process of mentoring researchers that currently privileges researchers in high-income countries. We provide examples of documents, such as cover letters, that might not be available to LMIC researchers. These examples serve as models for researchers who are learning to create effective arguments and to follow writing conventions. In high-income countries, such examples are typically provided by a researcher's mentor. Our examples are contributed by colleagues in our peer review network (available on our website: https://sites.google.com/ umich.edu/prepss/for-authors/cover-letters).

\section{METRICS OF SUCCESS}

Our most important metric of success is the number of articles that have been published with our support, in peer-reviewed journals.

In our Research Training Programme, we have had 46 manuscript submissions to date (14 December 2019) the most recent batch was submitted a month prior to writing this paper. About half of these manuscripts come from participants who have attended a PREPSS author workshop, though all participants are invited to submit papers. So far, seven of these articles have been published in peer-reviewed journals, one is under review at a journal and four have been submitted to journals. The rest of the manuscripts are in various stages of the PREPSS review process (see table 3 ).

In our Journal Partners Programme, we have had six submissions to date. Authors in this programme have moved through our process much more quickly than authors in our other programme. Half of the submissions from the Journal Partners Programme are already under rereview with the original journals to which they were submitted. This difference in turnaround time is likely due to two factors: (1) PREPSS involvement occurred at a much later stage of manuscript development (the papers were formally prepared for journal submission) and (2)

\section{Table 3 Status of each manuscript submission to PREPSS, to date ${ }^{\star}$}

\begin{tabular}{|c|c|c|c|}
\hline & $\begin{array}{l}\text { Research Training } \\
\text { Programme }\end{array}$ & $\begin{array}{l}\text { Journal Partners } \\
\text { Programme }\end{array}$ & $\begin{array}{l}\text { Research Partners } \\
\text { Programme }\end{array}$ \\
\hline Manuscript under initial PREPSS review & 4 & & $\begin{array}{l}\text { Waiting for initial } \\
\text { submissions }^{\star \dagger}\end{array}$ \\
\hline $\begin{array}{l}\text { Manuscript under second or third round of PREPSS peer } \\
\text { review }\end{array}$ & 1 & 1 & \\
\hline Awaiting author revision after PREPSS peer review & 16 & 2 & \\
\hline $\begin{array}{l}\text { PREPSS services (peer review and copy editing) complete. } \\
\text { Awaiting status update from author }{ }^{\dagger \ddagger}\end{array}$ & 4 & & \\
\hline $\begin{array}{l}\text { Author submitted manuscript to peer-reviewed journal and } \\
\text { is awaiting decision }\end{array}$ & 7 & & \\
\hline Manuscript under peer review at journal & & $3^{\ddagger \S}$ & \\
\hline Manuscript under revision at peer-reviewed journal & 1 & & \\
\hline \multirow[t]{2}{*}{ Manuscript published in peer-reviewed journal } & 7 & & \\
\hline & 40 & 6 & \\
\hline
\end{tabular}

*As of 14 December 2019.

tWe expect our first submissions in January 2019.

$\ddagger$ We check in with authors every 3 months to offer further assistance and for status updates.

$\S$ Manuscripts are being rereviewed by the PREPSS partner journal who referred the author for services.

PREPSS, Pre-Publication Support Service. 
the manuscripts were hand-selected for quality by journal editors.

We have not yet received any manuscript submissions from our Research Partners Programme (our first Research Partners Programme training session took place in December 2019) but we anticipate that this will be a successful model as support from PREPSS begins after data collection and analysis, when researchers are poised to develop manuscripts.

Prior to receiving our services, we ask consenting PREPSS authors to complete a short survey to help us assess the need for and impact of the services we provide. Our preliminary results demonstrate a need for the writing instruction, peer-review and copy editing services that PREPSS provides. Before working with PREPSS, roughly half of 45 researchers expressed that they were not confident or neutral that they could prepare a manuscript that would be accepted for publication by a highly regarded journal in their discipline. Similarly, about twothirds of these participants were not confident they knew of a person to ask if they had a question about presenting a result in a manuscript they were preparing. Further, $89 \%$ of these participants anticipated needing copy editing for grammar, spelling and writing quality.

\section{LESSONS LEARNT}

We have learnt a great deal in the past 2 years. Building and managing a growing organisation comes with many logistical and operational challenges.

Our biggest challenges involve defining a new model of author support to fill a major need. Though our activities feel familiar to our PREPSS peer reviewers and copy editors, the roles are different than those of traditional peer reviewers and copy editors in some important ways.

Early on, some of our reviewers expressed discomfort with PREPSS peer reviewer responsibilities as compared with those for a traditional journal. PREPSS reviewers rigorously evaluate papers using standard criteria similar to a journal peer review. However, reviewers are sometimes asked to evaluate studies that fall outside their area of expertise. This is because we expect that after PREPSS peer review, a paper will be reviewed again by journal peer reviewers who are content experts. We now clearly communicate to new PREPSS peer reviewers that our goal is to help authors get in the door at a peer-reviewed journal rather than to produce a publication-ready paper.

During the first several months of operation, some PREPSS peer reviewers felt overwhelmed by manuscripts with spelling, grammar and formatting issues. They noted in their evaluations that they felt responsible to address these issues even though copy editing does not fall under a traditional peer reviewer role. We now communicate that we do not expect peer reviewers to copy edit manuscripts. In fact, we explicitly ask peer reviewers to avoid copy editing manuscripts, emphasising that it is not efficient to make such edits before or during peer review.
Box 1 Help us promote equity in global health research

Our organisation provides mutual benefit to peer reviewers, copy editors and authors. Authors receive valuable support in publishing their original research in academic journals. Peer reviewers and copy editors have the opportunity to contribute to greater research equity. Student reviewers gain valuable professional skills and a deeper understanding of issues surrounding disparities in global health research. Finally, everyone on the Pre-Publication Support Service (PREPSS) team is part of a diverse professional network.

Our success is not possible without support from the research community. Please consider applying to participate as a PREPSS peer reviewer. The commitment is two reviews per year, and each review will count as a service activity to the academic community. To apply, email Ella August at prepssadmin@umich.edu. If you are interested in hosting a student peer reviewer training workshop led by August at your institution, please contact Ella August at prepssadmin@ umich.edu. If you would like information about partnering with PREPSS for author training and support, please contact Ella August at prepssadmin@umich.edu.

This is because large changes, including the deletion of large sections of text, render many copy edits irrelevant.

Likewise, copy editors initially struggled to adapt their traditional role to the prepublication setting. In many cases, journals provide detailed copy editing; we do not want to duplicate these services. We adjust our copy editing services to the author's target journal. If an author's target journal does not offer copy editing, we provide comprehensive copy editing. But if an author plans to submit to a journal that does provide copy editing, we offer a basic service that produces a smooth, clean and readable product.

Finally, journals have been slow to appreciate the power of the PREPSS model. We found our existing journal partners for the Journal Partners Programme after many offers of free support to international and regional African journals. We anticipate that acceptance of the PREPSS model will become more widespread with time and as we become more established.

\section{CONCLUSION}

The PREPSS model is one of many potential interventions that will be necessary to restructure global health research in order to reduce current colonial power imbalances. It is our hope that, in strengthening capacity for scientific writing and publishing in low-resource settings, local perspectives will be better represented in the global health literature. We hope that this, in turn, will lead to better local funding and transfer of power to local structures, which are the most effective vehicles for positive change. Please see box 1 for information on how to get involved with PREPSS.

Twitter Ella August @Ellainthemitten

Acknowledgements We thank the researchers who participated in PREPSS training workshops and those who submitted their manuscripts to PREPSS for review and copy editing. Additionally, this work is supported by the PREPSS staff, 
the volunteer peer reviewers and the copy editors. We very much appreciate the feedback given by our colleagues on our draft manuscript.

Contributors EA roles: substantial contributions to the conception or design of the work-acquisition, analysis and interpretation of data for the work-drafting the work-revising it critically for important intellectual content-final approval of the version to be published and-agree to be accountable for all aspects of the work in ensuring that questions related to the accuracy or integrity of any part of the work are appropriately investigated and resolved. CB: Acquisition, analysis and interpretation of data for the work-drafting the work-revising it critically for important intellectual content-final approval of the version to be published andagree to be accountable for all aspects of the work in ensuring that questions related to the accuracy or integrity of any part of the work are appropriately investigated and resolved. Contributors also include researchers who participated in PREPSS training workshops and those who submitted their manuscripts to PREPSS for review and copy editing. This work is supported by the PREPSS staff, the volunteer peer reviewers and the copy editors.

Funding Our funding is provided by our partners and through grant funding since we launched the non-profit NGO in 2017.

Competing interests EA is the founder and Editor-in-Chief of Pre-Publication Support Service and CB is the Associate Editor of Pre-Publication Support Service.

Patient consent for publication Not required.

Provenance and peer review Not commissioned; internally peer reviewed.

Data availability statement The data we present in this article are from our clients and are private. For this reason, we are not sharing the data.

Open access This is an open access article distributed in accordance with the Creative Commons Attribution Non Commercial (CC BY-NC 4.0) license, which permits others to distribute, remix, adapt, build upon this work non-commercially, and license their derivative works on different terms, provided the original work is properly cited, appropriate credit is given, any changes made indicated, and the use is non-commercial. See: http://creativecommons.org/licenses/by-nc/4.0/.

ORCID iDs

Clara Busse http://orcid.org/0000-0002-0178-1000
Ella August http://orcid.org/0000-0001-5151-1036

\section{REFERENCES}

1 Hedt-Gauthier BL, Jeufack HM, Neufeld NH, et al. Stuck in the middle: a systematic review of authorship in collaborative health research in Africa, 2014-2016. BMJ Glob Health 2019;4:e001853.

2 Mbaye R, Gebeyehu R, Hossmann S, et al. Who is telling the story? A systematic review of authorship for infectious disease research conducted in Africa, 1980-2016. BMJ Glob Health 2019;4:e001855.

3 Kelaher M, Ng L, Knight K, et al. Equity in global health research in the new millennium: trends in first-authorship for randomized controlled trials among low- and middle-income country researchers 1990-2013. Int J Epidemiol 2016;45:2174-83.

4 Fong $\mathrm{H}$, Harris E. Technology, innovation and health equity. Bull World Health Organ 2015;93:438-438A.

5 Beran D, Byass P, Gbakima A, et al. Research capacity buildingobligations for global health partners. Lancet Glob Health 2017;5:e567-8.

6 Nafade V, Sen P, Pai M. Global health journals need to address equity, diversity and inclusion. BMJ Glob Health 2019;4:e002018.

7 Bhaumik S, Jagnoor J. Diversity in the editorial boards of global health journals. BMJ Glob Health 2019;4:e001909.

8 Langer A, Díaz-Olavarrieta C, Berdichevsky K, et al. Why is research from developing countries underrepresented in international health literature, and what can be done about it? Bull World Health Organ 2004;82:802-3

9 Netzel R, Perez-Iratxeta C, Bork P, et al. The way we write. Countryspecific variations of the English language in the biomedical literature. EMBO Rep 2003;4:446-51.

10 Horton R. North and South: bridging the information gap. Lancet 2000;355:2231-6.

11 Harris E. Building scientific capacity in developing countries. EMBO Rep 2004;5:7-11.

12 Abimbola S. The foreign gaze: authorship in academic global health. BMJ Glob Health 2019;4:e002068.

13 Trostle J. Research capacity building in international health: definitions, evaluations and strategies for success. Soc Sci Med 1992;35:1321-4. 